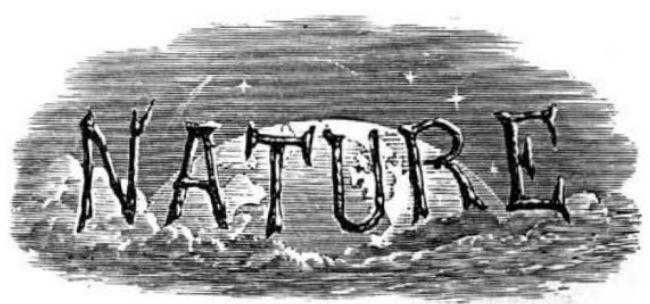

SATURDAY, MARCH 20, 1926.

\title{
CONTENTS.
}

PAGE

The Coal-mining Industry in Great Britain. By Prof. H. Louis

Egyptian Archæology. By Sir Flinders Petrie, F.R.S.

Agricultural England and Wales

Experimental Optics. By Prof. J. A. Crowther

Our Bookshelf . • 4 II

Letters to the Editor:

International Phenology.-J. Edmund Clark . 4I3

Zoological Nomenclature.-Dr. C. W. Stiles • 4I4

The Isomeric Chromic Chloride Hexahydrates.Prof. J. R. Partington and S. K. Tweedy . 4I5 On Nocturnal Colour Change in the l'ea-crab (Pinnotheres veterum). - D. Atkins . . .

Magnetic Storm of February 23-25, 1926.-H. W. L.

Absalom Nymmetric Nitrogen Atoms in Natural Products.-
Asym

Prof. T. M. Lowry, F.R.S. .
Abnormalities produced by Amniotic Pressure, and their Relation to Heredity.-J. T. Cunningham

On the Polarised Emission of Mercury Lines. H. W. B. Skinner

The Leaping Salmon.-W. L. Calderwood .

Re-Paging of Reprints. - Dr. R. H. Rastall .

On One-Eyed Vision. - Sir Oliver Lodge, F.R.S.

Peregrine Phillips, the Inventor of the Contact Process for Sulphuric Acid. By Sir Ernest Cook, D.Sc.

Seasonal Sunshine in Great Britain. By Chas. Harding

News and Views

Our Astronomical Column

Research Items

Archæology and Natural History in Lithuania .

Annual Meeting of the Association of Technical Institutions .

The Fate of the Hexosephosphoric Acid Esters in the Mammalian Organism

Contemporary Birthdays . . . . . . 436

Societies and Academies $\quad . \quad$. $\quad . \quad$. $\quad . \quad 436$

Official Publications Received . . . . . . . 439

Diary of Societies and Public Lectures . . . . 440

Editorial and Publishing Offices:

MACMILLAN \& CO., LTD.,

ST. MARTIN'S STREET, LONDON, W.C. 2.

Editorial communications should be addressed to the Editor. Advertisements and business letters to the Publishers.

Telephone Number: GERRARD 8830.

Telegraphic Address: PHUSIS, WESTRAND, LONDON.

\section{The Coal-mining Industry in Great Britain.}

THIS eagerly expected Report of the Coal Commission, which was issued on March II, constitutes a document of the highest interest and importance (H.M.S.O.; is. net). The Commissioners evidently have been impressed by the gravity of the situation and the magnitude of the task entrusted to them, and have spared no pains in making a complete investigation of the questions involved.

It may be said at once that, as might be expected from the exceptional qualifications of the Commissioners, the report is an eminently sound and sane one, and the best evidence of this lies in the fact that it has impartially dissatisfied all parties to the dispute. It is too often forgotten that there are at least three parties concerned, namely, the miners, the mineowners, and the general public: the first two are articulate, not to say vociferous; the third is so inarticulate that its interest, vital though it is, is too frequently overlooked. It is sincerely to be wished, though the hope is scarcely likely to be realised, that the public would bestir itself sufficiently to read this report and would for once find a means of expressing its views.

It is obviously impossible to discuss in detail so voluminous a report; only a few of the main recommendations can here be considered. Perhaps the recommendation which will impres's most people is that coal royalties shall be acquired by the State by purchase from their present owners. There is no fault at all to find with the principle of State ownership of minerals; as a matter of fact the greater portion of the minerals in the world are owned by the States within the territories of which they lie and are granted to mine-workers in the form of concessions. The most striking exceptions to this general method are to be found in Great Britain and the United States, where the minerals are the property of individuals or have been acquired by them. Incidentally it may be noted that these are the two countries in which mining has made the most progress and in which the wages of miners are the highest; this fact may be only a coincidence, or it may possibly be more deeply rooted than we are able to see at present in the condition of private ownership of the minerals.

The Commissioners amply justify the position that royalties are a perfectly legal form of ownership, and that if the State desires to acquire them it will have to pay for them. Their reasons are set out in the historical account which they give of royalties, but they by no means present the case in its entirety, because it is in fact much stronger than the report would lead the reader to believe; the opinion of the Commissioners that the State should now repair the error which it made when it parted with these royalties would lead the reader to infer that the State had at one time possessed these coal royalties. Such, however, is far from being the case: the State, or rather the Crown, in the past repeatedly claimed the ownership of metalliferous minerals, but never at any time set up the slightest claim to an ownership of coals.

Ownership of land and all that pertains to land in England dates from the Norman Conquest, and it is significant that the Doomsday Book, though it

NO. 2942, VOL. I I 7 ] 
mentions other mines, never once mentions a coal mine, so that it may fairly be inferred that at the date of the Conquest no coal mines existed in England. The earliest document concerning coal mines of which we have any knowledge is a Scotch deed dated 1202 , in which the superior granted a lease of certain collieries in Newbattle, and even at this period the absolute right of the land-owner to dispose freely of his coal appears to have been unquestioned, and has remained so until the present day. As stated by the Commissioners, the Great Case of Mines settled the rights of the land-owner to mines within his land, as has been very clearly set forth by Sir John Pettus in his Fodine Regales, published in 1670. Apparently the first mention of coal mines in legislation appears to have been in the well-known Statute of Elizabeth in 1601 , which instituted the Poor Rate and empowered the overseers of the poor to levy such rate upon any occupier of lands, houses, coal mines, etc. It is highly significant that this Act excludes other mines from the operation of the Poor Rate, and assimilates coal mines to houses and other appurtenances of the land. In England, therefore, the State never parted with the ownership of coal mines, for the simple reason that it never owned them, and it is obvious that if it now wishes to acquire them, it can only do so by purchase. The Commissioners suggest that a purchase price of $100,000,000 l$. would be a fair equivalent; this price is only sufficient if royalty owners consent to accept a lower income than they are at present receiving on condition that it shall be in a more secure form, and the suggestion is not an unreasonable one.

Whilst the principle of State acquisition of royalties is clear enough, its execution bristles with difficulties, not a few of which the Commissioners, to do them justice, have foreseen and have endeavoured in part to meet. The principle which they propose, namely, that coal, the existence of which is not to-day proved, shall belong to the State, is a perfectly defensible one, though curiously enough they have missed the main argument in its favour. It is certain that such coal can only be discovered as the result of the exact knowledge of the geological structure of the country, which has been obtained by the labours of a public department, namely, the Geological Survey, to the maintenance of which every taxpayer has contributed. It is difficult to see why a Kentish farmer who has bought land purely for agricultural purposes should claim the ownership of the coal which happens to lie under that land, when he has contributed to the discovery of that coal nothing more than has an equally taxed person in any other part of the country.

The Commissioners have evidently realised, as every one who knows the industry must realise, that, if it is to survive, the cost of production must come down, and as two-thirds of this consists of wages, it is obviously here that the greatest economies are possible; of the alternatives, either of lowering wages or of increasing the hours of labour for the same wage, the Commissioners pronounce in favour of the former. It does seem, however, that they have not looked at the question of length of the working day from the proper point of view. Their main argument against increasing the length of the working day is that if it were so increased in Great Britain as to be brought up to the level of our principal competitors, these would immediately increase the length of their working day. Obviously the same argument might apply to a lowering of wages, but there is not a particle of evidence that anything of the kind would happen.

Surely the proper way to approach the question of the length of a working day is to determine whether an increase of hours would unduly overtax the workers. Those who remember that, not so many years ago, the length of the working day was something like 50 per cent. more than it is to-day, and that men engaged in the even more arduous work of metal mining to-day work longer hours than coal miners, would unhesitatingly declare that the length of the coal miners' working day could be lengthened without inflicting the slightest hardship upon them. There is another alternative which never seems to have been placed before the Commissioners; even if it be suggested that a man who is hand-hewing in hard steam coal for six and a half hours has done as much physical work as can fairly be expected of him, the same cannot be said of the man whose work is running a coal-cutter, and it would appear to be a wise policy to have recommended that the hours of the men working in machine-cut faces should be lengthened. No doubt such a recommendation would present certain difficulties in practice, especially in mines where some districts are hand-cut and others machine-cut, but these difficulties would not appear to be insuperable. The recommendation would have the advantage of more nearly equalising the demands made upon the men, and it would encourage the more extensive use of machinery underground, because it would thus enable owners who put in machinery to get a better return on the capital thus invested.

It is rather surprising to find that in the chapter on profits, as indeed throughout the report, the wasting nature of the industry is nowhere recognised, and the fact is missed that it is necessary to make provision for the capital sunk in a colliery which must be replaced out of revenue before anything like a profit can be earned. The Commissioners estimate that to purchase the collieries of Great Britain would cost $350,000,000 l$.; as the annual output of the country may be averaged at $250,000,000$ tons, this amounts to a capitalisation of $28 s$. per ton per annum. If it is assumed, as the Commissioners appear to suggest, that the average life of a colliery may be expected to be about forty years, it is not difficult to calculate what sinking fund would be required to replace the above capital. Assuming the interest on gilt-edged securities to be $4 \frac{1}{2}$ per cent., and that income-tax remains as at present $4 s$. in the $l$, the annual amount to replace the capital outlay would be as nearly as possible $4 d$. per ton, thus reducing the real profit from the figure of $\mathrm{I} s$ given by the Commissioners to $8 d$. Furthermore, the Treasury most unjustifiably charges income-tax on the aforesaid $4 d$., although, as just pointed out, it is not profit at all but merely a replacement of capital, so that the nominal profit of $x$. is thus cut down to $7 d$. Incidentally it may be suggested that if the Treasury were to refrain from collecting income-tax, which is strictly speaking a tax on profits, from that portion of the income of colliery owners which serves only to replace the capital sunk in the collieries, the nucleus of a fund could be formed which might help to tide the industry over difficult times.

$$
\text { NO. 2942, VOL. I I } 7 \text { ] }
$$


Probably the most difficult point which the report discusses is the problem of what the industry is to do in May next. The Commissioners are quite clear on the point that the subsidy must not be renewed in any form whatever, and the figures which they present make their reason abundantiy clear. It is shown that the subsidy has been employed to pay hewers at the high rate of $76 \mathrm{~s}$. per week on the average, or as much as gos. per week in some districts, whilst it has enabled certain collieries to make quite handsome profits. It is clear enough that neither wages on so high a scale as this nor dividends to shareholders in collieries ought ever to he paid out of the pockets of taxpayers. It is, however, very difficult indeed to see how the industry is going to tide over the next few months without assistance of some kind, because the returns from the industry itself are not sufficient to pay what may be considered a reasonable wage to the lower paid men. The Commissioners, like all intelligent men, realise that the only wages which any industry can pay in the long run are the proceeds of the industry itself, although the Commissioners have not always expressed this clearly; for example, in discussing the policy of the subsidy, they speak of a gap "between the amounts that employers are willing to pay and the amounts that the workers are willing to accept" ; it is not a question of what the employers are willing to pay but what they are able to pay ; it cannot be too often repeated that the employers do not find the money wherewith to pay wages, they are merely the medium through which the money realised by the industry is handed over to the workers.

The Commissioners realise fully that if the various recommendations which they make are carried out, and if they have, as they well may have, the desired effect of re-establishing the industry, this will be a matter of time, and they do not indicate how the industry is to exist meanwhile. It is possible that some means might be found of tiding over the period of struggle which lies before the industry by an advance from the State, say on the joint guarantee of repayment by the Miners' Federation and the Mining Association, such advances to be used solely for keeping the wages of the lower paid men above subsistence level and not to pay high wages to the higher paid men or dividends to the colliery owners.

In any case, and whatever is done, all engaged in the coal industry must make up their minds to bear their share of the hardships which will have to be faced. As the Commissioners point out, the War has to be paid for, and they show "how impossible it is to insist that real wages shall in no case be below those ruling before the War." Men in the sheltered industries have been able to secure this unfair advantage, and have thus thrown an additional burden on those engaged in the competitive industries, and there seems no alternative but for the latter to shoulder it. Whilst in the words of the Commissioners in discussing the coal industry "the only generalisation about it that is safe is that no generalisation is possible," this much is certain : neither the Commissioners nor any one else can find any royal road by which the industry can be brought to the desired condition of prosperity, and the only avenue by which that goal may be reached for all engaged in the industry, whoever they may be, is hard work and privation.

H. Louis.

\section{Egyptian Archæology.}

(I) The Mummy: a Handbook of Egyptian Funerary Archaology. By Sir E. A. Wallis Budge. Second edition, revised and greatly enlarged. Pp. xxiv + $5^{\mathrm{I}} 3+39$ plates. (Cambridge: At the University Press, 1925.) 45s. net.

(2) Egyptian Religion and Ethics. By F. W. Read. Pp. viii $+\mathrm{r}_{52}+6$ plates. (London: Watts and Co., I925.) 4s. 6 d. net.

(x) T THLE Egypt has been fortunate in having a preservative climate and an industrious and artistic people who portrayed all its life, it has suffered by the rise of the Nile bed burying its early habitations under the ground. The prominence thus given to the tombs on the desert, as our main source of information, and the popularity of mummies, has led to a false idea of the importance of the funeral rites. This is further enforced when an encyclopædia of Egyptian usages, like the first volume under notice, is called "The Mummy," though that subject does not occupy a twentieth of its bulk. The greater part of the volume deals with the more interesting subjects of the history and language and the objects of utility; thus the living rather than the dead Egyptian is the object of this work.

A brief running account of the history of the kingdom occupies sixty pages on well-known lines, scarcely touching the long prehistoric ages. The list of principal kings' names in hieroglyphics further fills forty pages. A like space is given to a full recital of the stages in the decipherment. of the method of writing, showing how far the different scholars carried it between Akerblad in $\mathrm{r} 802$ and Hincks in $\mathrm{x} 848$; this is illustrated by the finest photograph yet taken of the Rosetta stone. The principal hieroglyphs are listed in twenty-five pages, and rather more is given to a list of amulets and figures of gods, with some account of each. The description of usual tombs and their accessories fills the last hundred pages. Thus the stock subjects are pretty fully dealt with, in the form required by a general reader for reference, without entering on the detail needed by a student. A work of this scope is much needed, and no other single volume fills its place.

The great length and continuity of civilisation in Egypt renders it, perhaps, the most important country for studying the nature of man. It was in continual change, its fashions fluctuating around a norm which varied but slowly; yet it was often invaded by fresh peoples, who in mind and body always became assimilated to its culture, until the last two thousand years. This aspect is scarcely touched on in "The Mummy" ; the distinctive changes in the history of the mirror, 